\title{
Tethering of Homo and Block Glycopolymer Chains onto Montmorillonite Surface by Atom Transfer Radical Polymerization
}

\author{
Amal Amin ${ }^{1 *}$, Heba Kandil', Ahmed Ramadan², Mohamed Nader Ismail ${ }^{1}$ \\ ${ }^{1}$ Polymers \& Pigments Department, National Research Center, Giza, Egypt \\ ${ }^{2}$ Chemistry Department, Faculty of Science, Helwan University, Cairo, Egypt \\ Email: aamin_07@yahoo.com
}

Received August 31, 2012; revised October 3, 2012; accepted October 14, 2012

\begin{abstract}
Well-defined homo glycopolymer/montmorillonite (MMT) nanocomposite (gly $)_{1}$ was prepared successfully by the "grafting from" technique from the modified surface of MMT via surface initiated atom transfer radical polymerization (SI-ATRP) of 3-O-methacryloyl-1,2:5,6-di-O-isopropylidene- $\alpha$-D-glucofuranose (gly) in the presence of $\mathrm{Cu}(\mathrm{I}) \mathrm{Br} / \mathrm{bi}$ pyridyl at $90^{\circ} \mathrm{C}$ in xylene. Well-defined diblock copolymers ( $\mathrm{gly}_{2}$, gly $_{3}$, gly $\mathrm{gl}_{4}$ and $\mathrm{gly}_{5}$ ) were also synthesized via the same technique by using comonomers of methylmethacrylate (MMA) or styrene (St) with glycomonomer (gly) using the same catalytic system. The formed nanocomposites showed both intercalated and exfoliated structures, as judged by XRD and TEM measurements. Further analyses were performed on such nanocomposites to confirm their formation such as TGA and DSC. The structures of the attached polymers to MMT were characterized by ${ }^{1} \mathrm{H}$ NMR.
\end{abstract}

Keywords: Glycopolymers; Polymer/Layered Silicates Nanocomposites; SI-ATRP; Montmorillonite

\section{Introduction}

In the recent decades, polymer/clay nanocomposites have attracted much attention as advanced polymeric materials on scientific level as well as in industry. Significant improvements in mechanical and physical properties of the resultant polymeric nanocomposites are recorded with respect to the pristine clay and the polymer matrix with low clay loading content [1,2]. These hybrid materials can combine the properties of both components (inorganic and organic), such as swelling, water uptake, mechanical characteristics, thermal behavior, biocompatibility and biodegradability [3]. Polymer/clay nanocomposites can be prepared by three methods, namely, solution exfoliation, melt intercalation and in situ polymerization [4]. In situ polymerization is one of the most common ways of achieving a highly efficient dispersion of layered silicate in a polymer [5]. One particular method of in situ polymerization that is used to obtain well defined grafted polymer onto clay surface is living/controlled radical polymerization techniques $[5,6]$. Grafting of polymers onto clay is done either by grafting on or grafting from techniques [7]. However, the later technique is much desirable and more effective because it produces high densities of the grafting polymer.Several methods are

*Corresponding author. used to graft polymer from the substrate. However, the most easy and successful one in producing well defined polymer with controlled polydispersities and predetermined molecular weight is the surface-initiated atom transfer radical polymerization technique (SI-ATRP) [7]. This approach allows the synthesis of uniform polymer layers of high grafting density, with tunable thicknesses via molecular weight control on surface. Recently, surface-initiated atom transfer radical polymerization (SI-ATRP) has been demonstrated as a useful tool for modification of different substrates such as silica, montmorillonite clay (MMT), gold surface, polymer films, silicon wafers, metal/metal oxide, paper or glass, latexes and carbon nanotubes (CNTs) affording various polymer brushes with desired structures, properties, morphologies and functions with high applicable values [7,8]. Glycopolymers are polymers with pendant saccharide residues which are characterized by their high hydrophilicity and water solubility so they can be used for specialized applications, such as artificial materials for a number of biological, pharmaceutical and biomedical uses [9]. Recently, glycopolymers have attracted much attention as a model system to study the specific molecular recognition functions of carbohydrate and their possible applications in biomedical materials and biosensors after the immobilization $[10,11]$. Consequently, due to their importance as 
biomaterials we thought to prepare glycopolymers/MMT nanocomposites via SI-ATRP for several future applications. Many trials were exerted to prepare low polydespersity glycopolymer brushes using different substrates [12-15]. However, to the best of our knowledge no reports are present on grafting of such polymers on clay surface. Therefore, in this communication, SI-ATRP was used to graft 3-O-methacryloyl-1,2:5,6-di-O-isopropylidene- $\alpha$-D-glucofuranoside (gly) as sugar methacrylate model monomer onto modified MMT surface and also SI-ATRP was used to graft MAIpGIc with MMA or St to prepare block copolymers containing glyco-units. The prepared glycopolymers/MMT nanocomposites will be used in biochemical and biomedical research such as molecular recognition processes, drug delivery systems, and also as surfactants.

\section{Experimental}

\subsection{Materials}

Montmorillonite (MMT) was purchased from SigmaAldrich (cationic $\left(\mathrm{Na}^{+}\right)$with exchange capacity $=0.88$ meq/g and surface area $39.3 \mathrm{~m}^{2} / \mathrm{g}$ ). 2, 2'-Bipyridyl (2, 2'-bpy, 98\%) was received from Fluka while other chemicals were provided from Sigma-Aldrich. The chemicals were used as received. Styrene (St) and methyl methacrylate (MMA) were purified by passing through basic alumina column and stored under argon.

\subsection{Instrumentation}

Infrared measurements were recorded by Jascow FTIR430 series infrared spectrophotometer in the range between 4000 and $400 \mathrm{~cm}^{-1}$. Proton nuclear magnetic resonance ( $\left.{ }^{1} \mathrm{HNMR}\right)$ spectra were obtained from JEOL-ECA $500 \mathrm{MHz}$ spectrometer at room temperature in $\mathrm{CDCl}_{3}$ or DMSO- $\mathrm{d}_{6}$. Thermal gravimetric analysis (TGA) were carried out by using TGA-50 SHIMADZU thermogravimetric analyzer under nitrogen atmosphere with heat ing rate $10^{\circ} \mathrm{C} / \mathrm{min}$. Differential scanning calorimetry (DSC) was performed on TA Instruments Q600 SDT system with heating rate $10^{\circ} \mathrm{C} / \mathrm{min}$ under nitrogen flow. $\mathrm{X}$-ray diffraction (XRD) measurements were performed by using Siemens D5000 diffractometer equipped with an intrinsic Germanium detector system. Number average molecular weights ( $\bar{M}_{n G P C}$ ) and molecular weight distribution values (PDI) were determined by gel per meation chromatography (GPC) using GPC-1100 Agilent technologies with refractive index detector and three ultrastyragel columns $\left(100-10^{4}-10^{5} \mathrm{~A}\right)$ connected in series. THF was mainly used as the eluent with flow rate $1 \mathrm{ml}$ $\mathrm{min}^{-1}$. The molecular weights were calibrated with polystyrene standards. Transmission electron microscopy (TEM) images were obtained from TEM-JEOL CO op- erated at $120 \mathrm{kV}$. In order to estimate the distribution of clay particles into the polymer matrix, all samples subjected to TEM measurements were ultrasonically dispersed in distilled water and drop-cast onto carboncoated copper grids.

\subsection{Synthetic Procedures}

\subsubsection{Modification of MMT by Bis (2-Hydroxypropyl) Ammonium Chloride (MMT-BHPAC) [16]}

MMT (10 g) was suspended in $1000 \mathrm{~mL}$ of deionized water at ambient temperature. Bis (2-hydroxypropyl) amine (BHPAC) (1.9 g, $15.0 \mathrm{mmol})$ was dissolved in a mixture of deionized water $(78 \mathrm{~mL})$ and concentrated hydrochloric acid (1.93 mL, $22.4 \mathrm{mmol})$ and slowly poured into the clay suspension. The suspension was stirred for 1 $\mathrm{h}$ at $80^{\circ} \mathrm{C}$ and at ambient temperature for $24 \mathrm{~h}$. The modified clay was filtered, washed several times with 1:1 mixture of water and ethanol. The MMT-BHPAC product was freeze-dried, crushed into powder with a mortar. It was characterized by FTIR and X-ray diffraction.

\subsubsection{Immobilization of the ATRP Initiator on the MMT Surface (MMT-Br) [17]}

$2 \mathrm{~g}$ of organo modified MMT was dispersed for $2 \mathrm{~h}$ in a mixture of triethyl amine (13.93 mL, $100 \mathrm{mM})$, and anhydrous THF (120 mL), followed by drop-wise addition of $17 \mathrm{~mL}$ of 2-bromoisobutyryl bromide $(150 \mathrm{mM})$ to the mixture at $0^{\circ} \mathrm{C}$. The mixture was magnetically stirred for $3 \mathrm{~h}$ at $0^{\circ} \mathrm{C}$ and then for another $10 \mathrm{~h}$ at room temperature. The mixture was diluted with additional THF, and then centrifuged till the decanted liquid became completely colorless. Next, the produced MMT-Br was washed with water to make it free from excess amine and filtrated then dried at $50^{\circ} \mathrm{C}$ for $48 \mathrm{~h}$. The resulting modified clay (MMT-Br) was used for the surface-initiated polymerization reactions. It was characterized by FTIR, TGA and $\mathrm{X}$-ray diffraction.

\subsubsection{Synthesis of 3-O-Methacryloyl-1,2:5,6- di-O-isopropylidene- $\alpha$-D-gluco-furanose Monomer (MAIpGlc or gly) [18]}

$10 \mathrm{~mL}$ of methacrylic anhydride $(67.1 \mathrm{mmol})$ was added drop wise to a stirred solution of 1,2:5,6-di-O-isopropylidene- $\alpha$-D-gluco-furanose (10 g, $38.4 \mathrm{mmol}$ ) in $50 \mathrm{ml}$ of absolute pyridine at room temperature. The mixture was heated at $65^{\circ} \mathrm{C}$ for $4 \mathrm{~h}$ and for another $1 \mathrm{~h}$ after the addition of $35 \mathrm{~mL}$ of water. The reaction mixture was allowed to be stirred for more $24 \mathrm{~h}$ at room temperature and then extracted three times with $50 \mathrm{~mL}$ of petroleum ether (boiling range, $30^{\circ} \mathrm{C}-70^{\circ} \mathrm{C}$ ). The organic layer was washed with $5 \%$ sodium hydroxide then with water, dried over anhydrous sodium sulfate, and concentrated in vacuo. The crude product was purified by flash silica gel 
chromatography with a 7:2:1 ethyl acetate:toluene:methanol mixture eluent to yield the sugar-carrying monomer as colorless oil (gly) which was characterized via FTIR and ${ }^{1}$ HNMR.

\subsubsection{Grafting of (gly) on MMT Surface Via SI-ATRP}

\subsubsection{Synthesis of Homo-Grafted Glycopolymer} $\left(\mathrm{gly}_{1}\right)$ / MMT Nanocomposite

To the polymerization flask, MMT-Br (0.2g), 2, 2'-bpy $\left(1.75 \times 10^{-4} \mathrm{~mol}\right)$, gly $\left(1.75 \times 10^{-2} \mathrm{~mol}\right)$ and $\mathrm{CuBr}(1.75 \times$ $\left.10^{-4} \mathrm{~mol}\right)$ were successively added, then the tube was closed under argon. Xylene (50\% v/v) and ethyl-2-bromoisobutyrate (2-EiBBr; $1.75 \times 10^{-4} \mathrm{~mol}$ ) were added in sequential order via dry and purified syringes at ambient temperature with continuous stirring under Argon. The reaction mixture was placed in an oil bath at $90^{\circ} \mathrm{C}$. At the end of reaction period, the polymerization was terminated and the reaction mixture was diluted with THF and was centrifuged for 4 times to get rid of the free polymers formed in solution. The polymer solution in THF was passed through neutral alumina oxide column to remove the catalyst and then it was precipitated in methanol. The precipitated polymer was dried in vacuo. To remove the copper contaminants from the nanocomposite, the product ( gly $_{1} / \mathrm{MMT}$ ) was washed with aqueous solution of disodiumsalt-ethylenediamine tetraacetic acid (EDTA-disodium salt) then with water and dried in vacuum at $40^{\circ} \mathrm{C}$.

\subsubsection{Synthesis of gly $y_{1}-\mathrm{b}-\mathrm{p}-\mathrm{MMA}$ ( gly $_{2}$ ) or gly1-b-p-St} (gly3)/MMT Nanocomposites

The nanocomposites comprising block copolymer such

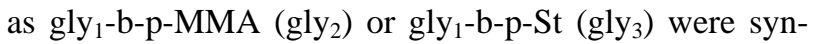
thesized using the same general procedure as previously mentioned in case of gly $_{1} / \mathrm{MMT}$ nanocomposites where gly $_{1} / \mathrm{MMT}$ nanocomposites was used as macroinitiator for further polymerization with MMA, St as the follow ing: gly ${ }_{1} / \mathrm{MMT}$ nanocomposites ( $0.1 \mathrm{~g}, \overline{\mathrm{M}}_{\mathrm{nGPC}}$ of gly $_{1}=$ $\left.5700 \mathrm{~g} / \mathrm{mol}, 1.75 \times 10^{-5} \mathrm{~mol}\right)$, bpy catalyst $\left(1.75 \times 10^{-5}\right.$ $\mathrm{mol})$ and $\mathrm{CuBr}\left(1.75 \times 10^{-5} \mathrm{~mol}\right)$ were added to round bottom flask under argon atmosphere. Xylene (50\% v/v), MMA or St $\left(1.75 \times 10^{-3} \mathrm{~mol}\right)$ and $2-\operatorname{EiBBr}\left(1.75 \times 10^{-5}\right.$ mol) were injected successfully via syringes under argon atmosphere with continuous stirring. SI-ATRP of MMA and St was carried out at $90^{\circ} \mathrm{C}$ and $110^{\circ} \mathrm{C}$, respectively.

\subsubsection{Synthesis of Block p-MMA-b-gly ( gly $_{4}$ ) or p-St-b-gly $\left(\right.$ gly $\left._{5}\right) / \mathrm{MMT}$ Nanocomposites via SI-ATRP}

Other block glycopolymers/MMT nanocomposites were prepared but in this method MMA or St were grafted onto MMT surface firstly and the resultant nanocompo- sites were used as macroinitiators for further SI-ATRP with glycomonomer (gly).

\subsubsection{C-1-Synthesis of p-MMA or P-St/MMT \\ Nanocomposites via SI-ATRP}

The same procedure that was used for synthesis $\left(\mathrm{gly}_{1}\right) /$ MMT nanocomposite was used for synthesis p-MMA or p-St/MMT nanocomposite as the following: The polymerization flask was charged under argon with MMT-Br (0.2 g), 2, 2'-bpy (1.75 × $\left.10^{-4} \mathrm{~mol}\right)$ and $\mathrm{CuBr}(1.75 \times$ $\left.10^{-4} \mathrm{~mol}\right)$, then xylene $(50 \% \mathrm{v} / \mathrm{v}), \mathrm{MMA}$ or St $(1.75 \times$ $\left.10^{-2} \mathrm{~mol}\right)$, and 2 -EiBBr $\left(1.75 \times 10^{-4} \mathrm{~mol}\right)$ were added. The reaction mixture was degassed by three freezepump-thaw cycles then placed in an oil bath at $90{ }^{\circ} \mathrm{C}$ in case of MMA and at $110^{\circ} \mathrm{C}$ in case of St.

\subsubsection{C-2- Synthesis of Block p-MMA-b-gly (gly4) or p-St-b-gly (gly5)/MMT Nanocomposites via SI-ATRP}

The used amounts of reactants will be as the following: For synthesis of gly $_{4} / \mathrm{MMT}$ nanocomposite, p-MMA/ MMT nanocomposite $\left(0.1 \mathrm{~g}, 1.5 \times 10^{-5} \mathrm{~mol}\right)$ was taken (where $\overline{M n G P C}$ of p-MMA $=6650 \mathrm{~g} / \mathrm{mol})$ with $(1.5 \times$ $\left.10^{-5} \mathrm{~mol}\right)$ from 2, 2'-bpy, $\mathrm{CuBr}, 2-\mathrm{EiBBr}$ and $\left(1.5 \times 10^{-3}\right.$ mol) from gly with $(50 \% \mathrm{v} / \mathrm{v})$ Xylene. The SI-ATRP was carried out at $90^{\circ} \mathrm{C}$. For synthesis of gly $y_{5} /$ clay nanocomposite, p-St/ MMT nanocomposite (0.1 g, $3.33 \times 10^{-5}$ mol) was taken (where $\overline{\mathrm{M}}_{\mathrm{nGPC}}$ of $\mathrm{p}-\mathrm{St}=3000 \mathrm{~g} / \mathrm{mol}$ ) with $\left(3.33 \times 10^{-5} \mathrm{~mol}\right)$ from 2, 2'-bpy, CuBr, 2-EiBBr and $\left(3.33 \times 10^{-3} \mathrm{~mol}\right)$ from gly with Xylene $(50 \% \mathrm{v} / \mathrm{v})$. The SI-ATRP was carried out at $90^{\circ} \mathrm{C}$.

\subsubsection{Deprotection of Isopropylidene Groups of Glycopolymer in (gly $/$ /MMT) Nanocomposite}

The deprotection process was carried out under mild acidic conditions [12] where $50 \mathrm{mg}$ of gly $\mathrm{y}_{1} \mathrm{MMT}$ nanocomposite were introduced into round flask containing $20 \mathrm{ml}$ of $80 \%$ formic acid. The reaction mixture was stirred for $48 \mathrm{~h}$ at room temperature. Then, $10 \mathrm{ml}$ of water were added and the mixture was stirred for more $12 \mathrm{~h}$. The solid product was then collected by centrifugation process. The final product $\left(\right.$ gly $\left._{6}\right) / \mathrm{MMT}$ nanocomposite was characterized by FTIR.

\subsubsection{General Procedure for Cleavage of the Grafted Polymers from the Clay Surface}

The grafted polymers brushes were cleaved from the surface of the clay with the method described by Böttcher et al. [19] where (0.1 g) of the polymer/clay nanocomposite in $20 \mathrm{mg}$ of p-toluene sulphonic acid was added to a mixture of $150 \mathrm{ml}$ toluene and $10 \mathrm{ml}$ methanol in $200 \mathrm{ml}$ round flask. The reaction mixture was heated under reflux for $72 \mathrm{~h}$. p-toluene sulphonic acid was used as a catalyst for cleavage of ester bond between clay sur- 
face and initiator. The cleaved polymer was separated from the solid material by centrifugation process. Subsequently, a small part of the isolated polymer was analyzed with GPC and ${ }^{1}$ HNMR to characterize the released polymers.

\section{Results \& Discussion}

The covalent attachment of the initiator moiety to the organo modified MMT surface was illustrated in Scheme 1 where MMT was modified firstly with BHPAC to in crease the grafting sites on its surface then treated with ATRP initiator. Esterification reaction occurred between 2-bromoisobutyryl bromide and hydroxyl groups that present in clay surface and organic modifier yielding macroinitiator. The macroinitiator consisted of reactive bromoisobutyrate groups capable of synthesizing homo and block glycopolymers/MMT nanocomposites by "graft from" technique using SI-ATRP (Scheme 1). All the polymerizations were carried out in the presence of a sacrificial initiator (2-EiBBr) which played an important role in allowing the polymerization to proceed in a controlled fashion, as its addition had to generate a sufficient concentration of persistent radicals as described else where $[7,20]$.

\subsection{Characterization of Organo Modified Mmt (MMT-BHPAC)}

The organic modification of clay was accomplished by cationic exchanging of bis-hydroxypropyl ammonium chloride (BHPAC) with the $\mathrm{Na}^{+}$ion on the clay surface. The modification was determined by FTIR and XRD. In FTIR, the characteristic peaks of modified MMT were appeared at $2932 \mathrm{~cm}^{-1}$ for $\mathrm{C}-\mathrm{H}$ and the broad peak at $3441 \mathrm{~cm}^{-1}$ for $\mathrm{O}-\mathrm{H}$ in organic modifier, whilst the peak for the Si-O group of the clay was present at $1046 \mathrm{~cm}^{-1}$. $\mathrm{X}$-ray diffraction (XRD) patterns provided evidence for the loading and intercalation of BHPAC between silicate layers by the increase in the interlayer distance from $\mathrm{d}=11.8 \AA\left(\mathrm{Na}^{+}\right.$spacing $)$to $\mathrm{d}=13.4 \AA$ as shown in Figure 1.

\subsection{Immobilization of Atrp Initiator onto Organo Modified Mmt (MMT-Br)}

The immobilization of ATRP initator onto organo modified MMT is of pivotal importance for anchoring polymer brushes onto the clay surface by ATRP. The insertion of ATRP initiator onto organo clay to form (MMT$\mathrm{Br}$ ) was confirmed with FTIR, TGA, XRD and TEM. In FTIR spectrum of MMT-Br, new peak appeared at 1717 $\mathrm{cm}^{-1}$ for $(\mathrm{C}=\mathrm{O})$. Also, a wide $\mathrm{OH}$ stretching vibration band appeared at $3373 \mathrm{~cm}^{-1}$ due to the surface hydroxyl groups. This particular band disappeared in initiator grafted samples. XRD analyses showed that the intercalation of ATRP initiator was successful. In XRD data (Figure 1), the d-spacing of layers increased by $1.84 \AA$, from $11.8 \AA$ in the neat MMT to $13.64 \AA$ in MMT-Br. Figure 2 showed the TGA traces of neat MMT clay and MMT$\mathrm{Br}$. Thereby, the observed changes in weight loss and in the thermal degradation onset for the MMT-Br are indicative of surface modification. The neat MMT showed very high thermal stability. The total weight loss was $8 \%$ till $900^{\circ} \mathrm{C}$. On the contrary, ATRP initiator anchored MMT (MMT-Br) showed a weight loss of around $18 \%$ up to $600^{\circ} \mathrm{C}$.

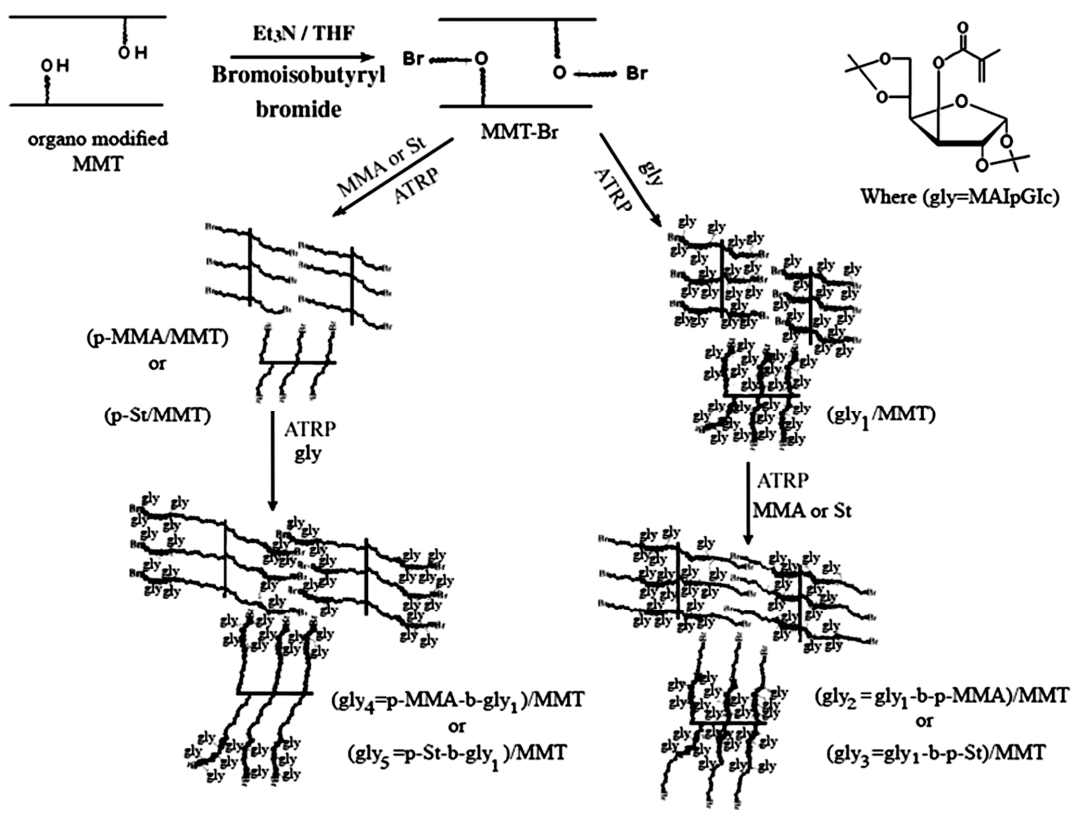

Scheme 1. SI-ATRP of homo and block glycopolymers onto MMT surface. 


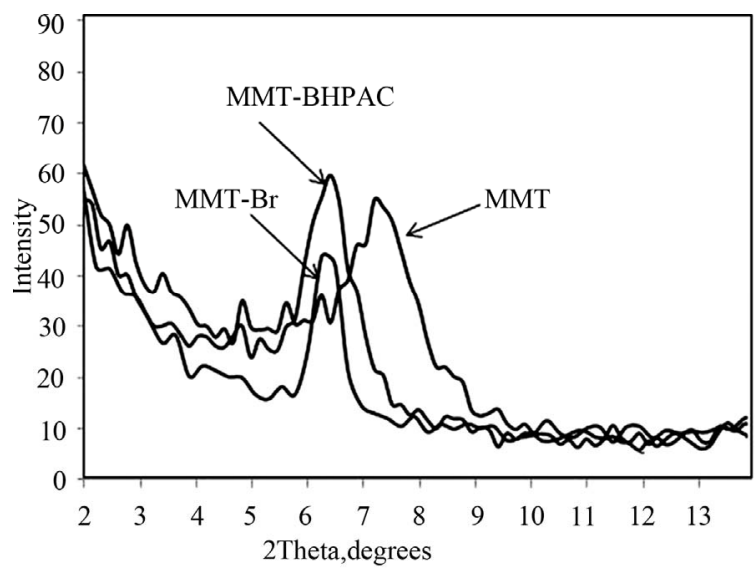

Figure 1. XRD of MMT, MMT-BHPAC and MMT-Br.

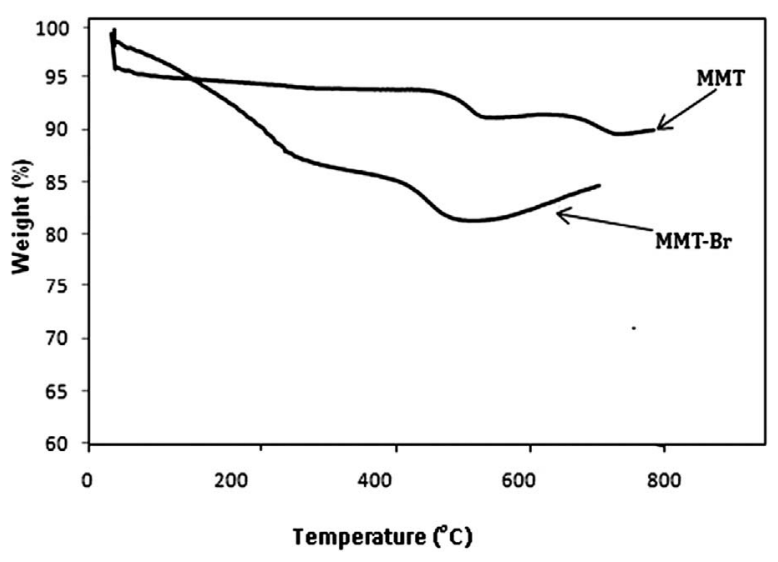

Figure 2. TGA of MMT and MMT-Br.

\subsection{Synthesis of Glycomonomer (MAIpGlc or gly)}

For synthesis of the glycomonomer (MAIpGlc, gly), the 1,2:5,6-di-O-isopropylidene- $\alpha$-D-gluco-furanose was reacted with methacrylic anhydride in the presence of base (absolute pyridine) as described in the literature [18].The chemical structure of the glycomonomer was identified by FTIR and ${ }^{1}$ HNMR. In FTIR spectrum, the functional groups of glycomonomer appeared at $2988 \mathrm{~cm}^{-1}(>\mathrm{C}=\mathrm{C}$ $<), 1725 \mathrm{~cm}^{-1}(>\mathrm{C}=\mathrm{O}), 1469 \mathrm{~cm}^{-1}\left(\mathrm{CH}_{3}-\mathrm{C}=\mathrm{C}\right)$ and at $1628 \mathrm{~cm}^{-1}\left(=\mathrm{CH}_{2}\right) .{ }^{1} \mathrm{H}-\mathrm{NMR}$ spectrum also confirmed the appearance of the characteristic peaks of the glycomonomer which appeared at $\delta 1.257-1.45\left(\mathrm{~m}, 12 \mathrm{H}, 4 \mathrm{CH}_{3}\right)$, 1.911 (s, $3 \mathrm{H}, \mathrm{CH}_{3}-\mathrm{C}=\mathrm{CH}_{2}$ ), 5.70, 6.07 (s, $2 \mathrm{H}, \mathrm{CH}_{2}=\mathrm{C}$ $<)$, 4.041, 4.246, 4.606, 5.08 and 5.78 (7H, sugar moiety). All the previous peaks confirmed the presence of double bond and carbonyl group in the formed glycomonomer (gly).

\subsection{Controlled Graft Polymerization of gly on the MMT-Br}

The living character of the grafting polymerization of gly as main monomer in our study on the clay surface was confirmed by the kinetic studies at various time intervals. Generally, the living polymerization is characterized by narrow polydispersity, linear increase in molecular weight with conversion, and the ability to extend the chains by sequential addition of monomer. Glycomonomer (MAIpGlc or gly) was involved in SI-ATRP to form its homopolymer $\left(\mathrm{gly}_{1}\right) /$ clay nanocomposites by using $\mathrm{MMT}-\mathrm{Br}$ in addition of using ethyl-2-bromoisobutyrate (2-EiBBr) as sacrificial initiator, 2, 2'-bipyridine (bpy) as ligand and $\mathrm{CuBr}$ at $90^{\circ} \mathrm{C}$ (Scheme 1). Table 1 summarized the results of the polymerization experiments of (gly) under various experimental conditions. The data indicated narrow polydispersity values and the molecular weight increased linearly with the polymerization time. Figure 3 displays the linear kinetic plots of $\operatorname{Ln}[\mathrm{M}]_{0} /[\mathrm{M}]_{\mathrm{t}}$ versus polymerization time. The linearity indicated that the polymerization method was approximately first order in monomer concentration.

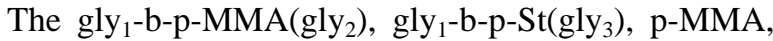
p-St, gly $_{4}$ and gly $_{5} / \mathrm{MMT}$ nanocomposites (Scheme 1) were obtained under similar reaction conditions of forming gly $_{1} / \mathrm{MMT}$ nanocomposite but in slower rates with relatively low polydispersity values with respect to the copolymers (Table 1). Generally, high number average molecular weights were recorded by $\operatorname{GPC}\left(\overline{\mathrm{Mn}}_{\mathrm{GPC}}\right)$ in case of gly $_{1}$, gly $_{2}$, gly $_{3}, \mathrm{p}-\mathrm{MMA}$, p-St, gly $\mathrm{y}_{4}$ and gly $\mathrm{y}_{5}$ more than the calculated ones which were attributed to relative slow initiation with respect to propagation step of the SI-ATRP reactions (Table 1). The free and bound polymers were characterized by GPC.

\subsection{Thermal Characterization of the Nanocomposites (TGA and DSC)}

With respect to TGA, gly , gly $_{2}$ and gly glost about $_{3}$ $20.3 \%$, $40 \%$ and $36.1 \%$ from their weights up to 670 , 630 and $620^{\circ} \mathrm{C}$. On the other hand, p-MMA, gly, $\mathrm{p}-\mathrm{St}$ and gly $_{5}$ lost about $32.67 \%$, 48.35\%, 31.73\% and 37.75\% of the weights of their samples approaching $650^{\circ} \mathrm{C}$, $600^{\circ} \mathrm{C}, 650^{\circ} \mathrm{C}$ and $630^{\circ} \mathrm{C}$ (Figure 4). DSC measurements revealed several $\mathrm{T}_{\mathrm{g}}$ values for the previously prepared glycopolymers nanocomposites. The measured values were $84.53^{\circ} \mathrm{C}$ for gly $_{1}, 84.53^{\circ} \mathrm{C} \& 225.17^{\circ} \mathrm{C}$ for gly $72.71^{\circ} \mathrm{C}$ for gly $_{3}, 70.24{ }^{\circ} \mathrm{C}$ for p-MMA, $52.34^{\circ} \mathrm{C} \&$ $173.46^{\circ} \mathrm{C}$ for gly $_{4}, 170.30^{\circ} \mathrm{C} \& 238.16^{\circ} \mathrm{C}$ for $\mathrm{p}-\mathrm{St}$ and $73.40^{\circ} \mathrm{C} \& 239.17^{\circ} \mathrm{C}$ for gly $_{5}$. As observed the two $\mathrm{T}_{\mathrm{g}}$ values were attributed to phase separation and confirming the nanostructures of the formed nanocomposites.

\subsection{Morphological Characterization of the Nanocomposites}

The degree of dispersion of the organo-modified MMT in the polymeric matrix in the formed nanocomposites 
Table 1. Data of SI-ATRP of gly on MMT surface at different times (synthesis of gly $/ \mathbf{y}_{\mathbf{1}} \mathrm{MMT}$ ).

\begin{tabular}{|c|c|c|c|c|c|c|c|c|}
\hline \multirow{2}{*}{ Entry } & \multicolumn{6}{|c|}{ Free polymer } & \multicolumn{2}{|c|}{ Bound polymer } \\
\hline & $\underset{\mathrm{h}}{\mathrm{Time}}$ & $\begin{array}{c}\text { Conversion } \\
\%\end{array}$ & $\overline{\mathrm{M}}_{\mathrm{nth}}$ & $\overline{\mathrm{M}}_{\mathrm{nGPC}} \mathrm{g} / \mathrm{mol}$ & PDI & $\operatorname{LnM}_{0} / \mathrm{M}_{\mathrm{t}}$ & $\overline{\mathrm{M}}_{\mathrm{nGPC}} \mathrm{g} / \mathrm{mol}$ & PDI \\
\hline gly $_{11}$ & 1 & 25 & 2500 & 3100 & 1.2 & 0.287 & 1100 & 1.4 \\
\hline gly $_{12}$ & 2 & 55 & 9000 & 11005 & 1.39 & 0.798 & 5700 & 1.32 \\
\hline gly $_{13}$ & 3 & 75 & 15000 & 19020 & 1.31 & 1.386 & 9510 & 1.3 \\
\hline gly $_{15}$ & 5 & 90 & 35000 & 48676 & 1.2 & 2.302 & 17023 & 1.25 \\
\hline gly $_{2} / \mathrm{MMT}$ & 24 & 57 & 27552 & 38586 & 1.34 & - & 15000 & 1.4 \\
\hline $\mathrm{gly}_{3} / \mathrm{MMT}$ & 24 & 34 & 16054 & 21139 & 1.4 & - & 9500 & 1.49 \\
\hline P-MMA/MMT & 4 & 34.7 & 15604 & 18271 & 1.14 & - & 6650 & 1.45 \\
\hline gly $_{4} / \mathrm{MMT}$ & 24 & 95 & 24248 & 29676 & 1.24 & - & 20045 & 1.33 \\
\hline P-St/MMT & 4 & 27 & 7120 & 9000 & 1.12 & - & 3000 & 1.23 \\
\hline gly $_{5} / \mathrm{MMT}$ & 24 & 72 & 16040 & 18000 & 1.32 & - & 9040 & 1.5 \\
\hline
\end{tabular}

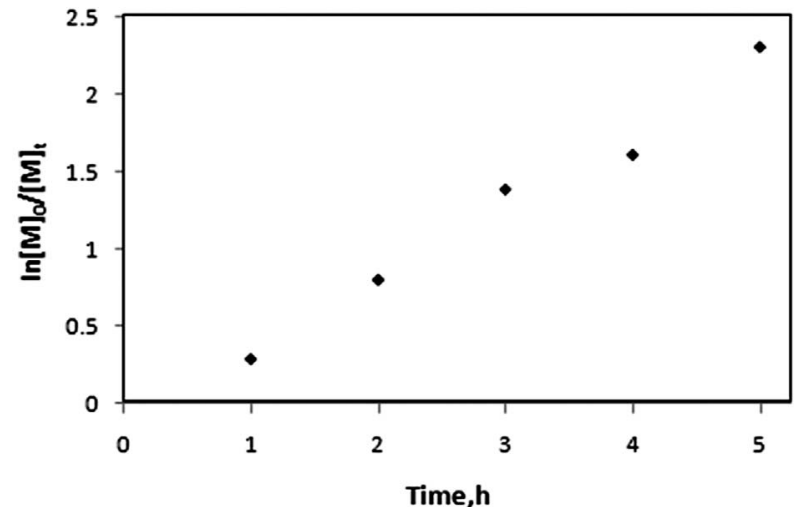

Figure 3. First order kinetic plot for SI-ATRP of gly.

was evaluated in each case using XRD. The XRD results showed no diffraction peaks (Figure 5(a)) for the nanocomposites gly , gly $_{3}$ and gly gl $_{4}$ while the nanocomposites

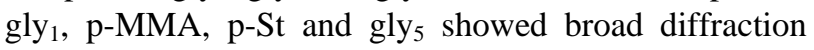
peaks that have been shifted towards lower $2 \theta$ angles (higher d-spacings) than that of MMT-Br as it is clear in (Figure 5(b)). TEM was also used to confirm the morphological structure of the formed nanocomposites where in gly $_{2}$, gly $_{3}$ and gly $_{4}$ images, disordered clay platelets being well dispersed in polymer matrices were observed (Figure 6). That fact led to conclusion that these nanocomposites showed exfoliated structures while in gly $_{1}$ and gly $_{5}$, partially exfoliated structures were obtained as revealed by TEM images (Figure 7) where both stacked intercalated and exfoliated silicate layers coexist. XRD confirmed those observations as previously mentioned.

\subsection{Structural Analysis of the the Grafted Polymers onto Clay Surface}

The chemical structures of the grafted polymers onto clay surface were confirmed by ${ }^{1} \mathrm{H}-\mathrm{NMR}$ analysis. ${ }^{1} \mathrm{H}-\mathrm{NMR}$ of gly $\left(\mathrm{CDCl}_{3}\right) \delta$ (ppm): 1.25 - $1.6\left(\mathrm{C}-\mathrm{C}_{3}\right.$, C-C $\underline{H}_{3} \mathrm{Br}, 4 \underline{\mathrm{CH}}_{3}$ of sugar moiety), 2 - $2.3\left(\mathrm{C}_{2}-\mathrm{C}-\mathrm{CH}_{3}\right)$,

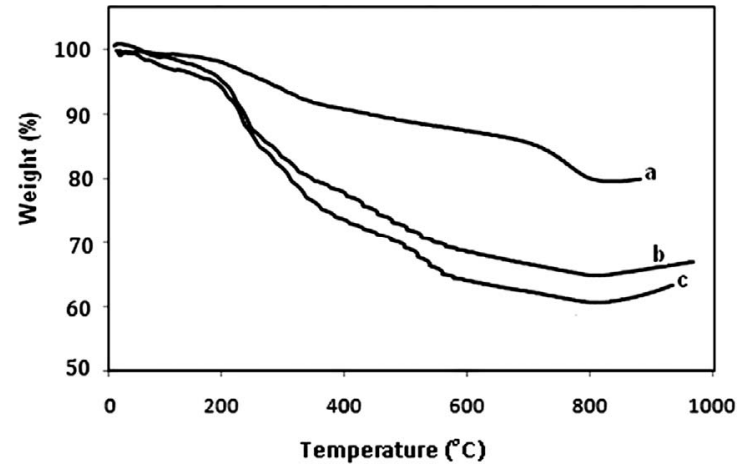

(a)

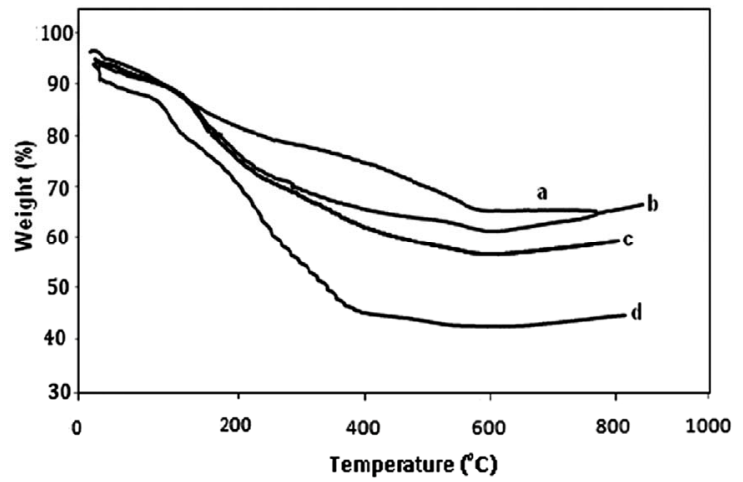

(b)

Figure 4. TGA of (a) a: gly $_{1}$, b: gly ${ }_{3}$ and c: gly $_{2} / \mathrm{MMT}$ nanocomposites; (b) a: p-St, b: p-MMA, c: gly and d: gly ${ }_{4} / \mathrm{MMT}$ nanocomposites.

$3.65\left(\mathrm{OCH}_{3}\right),(4.05,4.25,4.5,5.3,5.6,5.85, \mathrm{H}$ of sugar moiety). ${ }^{1} \mathrm{H}-\mathrm{NMR}$ of $\mathrm{gly}_{2}\left(\mathrm{CDCl}_{3}\right) \delta$ (ppm): 0.8 - 1.8 $\left(\mathrm{C}-\underline{\mathrm{H}}_{3}, \mathrm{C}-\mathrm{CH}_{3}-\mathrm{Br}\right), 2.2-2.3\left(\mathrm{CH}_{2}-\mathrm{C}-\mathrm{CH}_{3}\right), 3.6\left(\mathrm{CH}_{3}-\right.$ OCO), 3.7 ( $\left.\underline{\mathrm{C}}_{3} \mathrm{OCOCBr}\right), 4-5.9$ (H of sugar moiety).

${ }^{1} \mathrm{H}-\mathrm{NMR}$ of gly ${ }_{3}\left(\mathrm{CDCl}_{3}\right) \delta$ (ppm): 0.8 - $1.8\left(\mathrm{C}-\mathrm{CH}_{3}, 4\right.$ $\mathrm{CH}_{3}$ of sugar moiety), $2-2.2\left(\mathrm{CH}_{2}-\mathrm{CCH}_{3}, \mathrm{CH}_{2}-\mathrm{CHph}\right)$, 2.3 (Cㅍ-ph), 3.7 ( $\left.\mathrm{OC}_{3}\right), 6.9$ - 7.2 (ph), (4-5.9, H of sugar moiety). ${ }^{1} \mathrm{H}-\mathrm{NMR}$ for $\mathrm{p}-\mathrm{MMA}\left(\mathrm{CDCl}_{3}\right)$, the chemical shifts $(\delta, \mathrm{ppm}): 0.8-1.8\left(\mathrm{CCH}_{3}, \mathrm{CCH}_{3} \mathrm{Br}\right), 2-2.1$ 


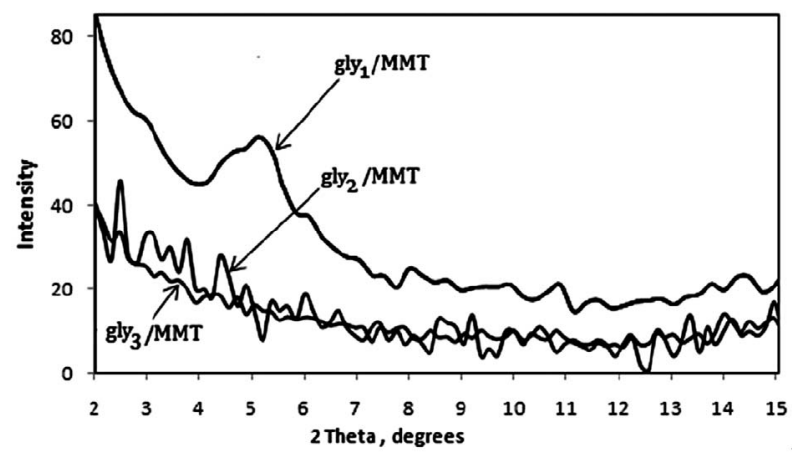

(a)

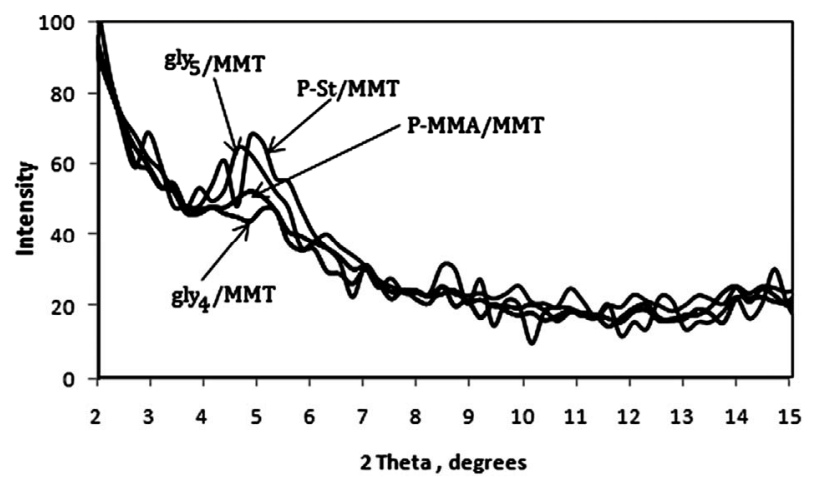

(b)

Figure 5. XRD of (a) gly $_{1}$, gly ${ }_{3}$ and gly $_{2} / \mathrm{MMT}$ nanocomposites (b) p-St, p-MMA, gly and $_{5}$ gly $_{4} /$ MMT nanocomposites.

$\left(\mathrm{CH}_{2} \mathrm{C}-\mathrm{CH}_{3}\right), 3.6\left(\mathrm{OCH}_{3}\right) .{ }^{1} \mathrm{H}-\mathrm{NMR}$ for $\mathrm{gly}_{4}\left(\mathrm{CDCl}_{3}\right)$, the chemical shifts $\left(\delta\right.$, ppm): 0.8 - $1.8\left(\mathrm{CCH}_{3}\right), 2.15$ - 2.35 $\left(\mathrm{CH}_{2}-\mathrm{CCH}_{3}\right)$, 3.5, 3.6, $3.75\left(\mathrm{CH}_{3} \mathrm{OCOCCH}{ }_{3}, \mathrm{CH}_{2} \mathrm{CCOO}-\right.$ $\mathrm{CH}_{3}$ ), 4 - 5.9 (H of sugar moiety). ${ }^{1} \mathrm{H}-\mathrm{NMR}$ for $\mathrm{p}-\mathrm{St}$ $\left(\mathrm{CDCl}_{3}\right)$, the chemical shifts $\left(\delta\right.$, ppm): $0.9-1.8\left(\mathrm{CCH}_{3}\right)$,

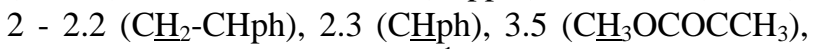
3.6 (Br-CH-ph), 6.5 - 7.3 (ph). ${ }^{1} \mathrm{H}-\mathrm{NMR}$ for gly ${ }_{5}\left(\mathrm{CDCl}_{3}\right)$, the chemical shifts $\left(\delta\right.$, ppm): $0.8-1.8\left(\mathrm{CCH}_{3}\right), 2-2.2$ $\left(\mathrm{C}_{2}-\mathrm{CCH}_{3}\right), 2.2$ (Cㅌph), $3.6\left(\mathrm{OC}_{3}\right), 4$ - 6.2 (H of sugar moiety), 6.8 - 7.4 (ph).

\subsection{Deprotection of Isopropylidene Groups in gly 1 /Clay Nanocomposite}

Deprotection of the gly $_{1} / \mathrm{MMT}$ in $80 \%$ formic acid led to formation of $\mathrm{OH}$-ended polymer $\left(\mathrm{gly}_{6}\right) / \mathrm{MMT}$ which was characterized by FTIR data. In the FTIR spectrum, the absorption peaks for C-H bonds at $2800-3100 \mathrm{~cm}^{-1}$ became weaker but the peak of hydroxyl group at 3400 $\mathrm{cm}^{-1}$ became stronger due to the cleavage of $\mathrm{CH}_{3}$-groups and the formation of hydroxyl groups. Thereby, the vibration of carbonyl group shifted to $1712 \mathrm{~cm}^{-1}$. Afterward, gly 6 was detached from its nanocomposite according to the previous mentioned method [11].The detached polymer gly ${ }_{6}$ was characterized by ${ }^{1} \mathrm{HNMR} .{ }^{1} \mathrm{H}-\mathrm{NMR}$ for gly $_{6}\left(\mathrm{DMSO}-\mathrm{d}_{6}\right)$, the chemical shifts $\left(\delta\right.$, ppm): $1\left(\mathrm{CCH}_{3}\right)$, 1.9 - $2.1\left(\mathrm{C}_{2}\right), 3.6\left(\mathrm{OC}_{3}\right), 4$ - 6 (H of sugar moiety),

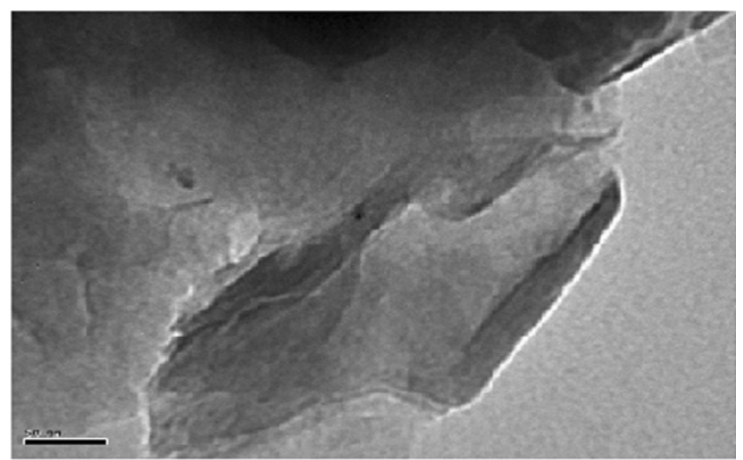

(a)

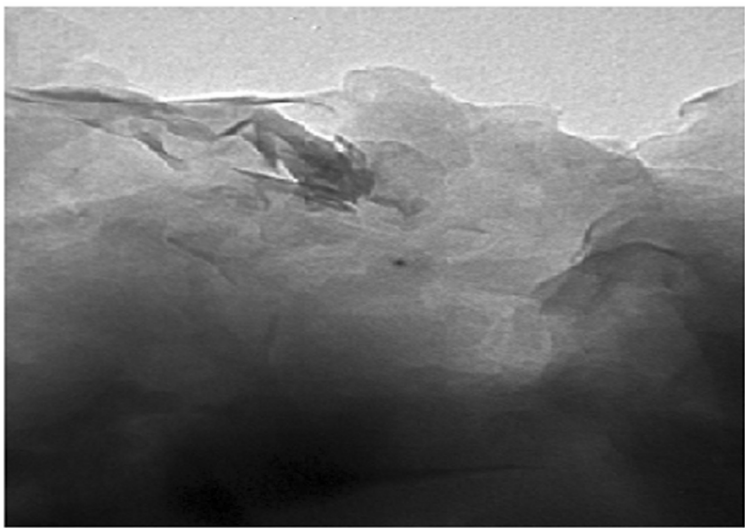

(b)

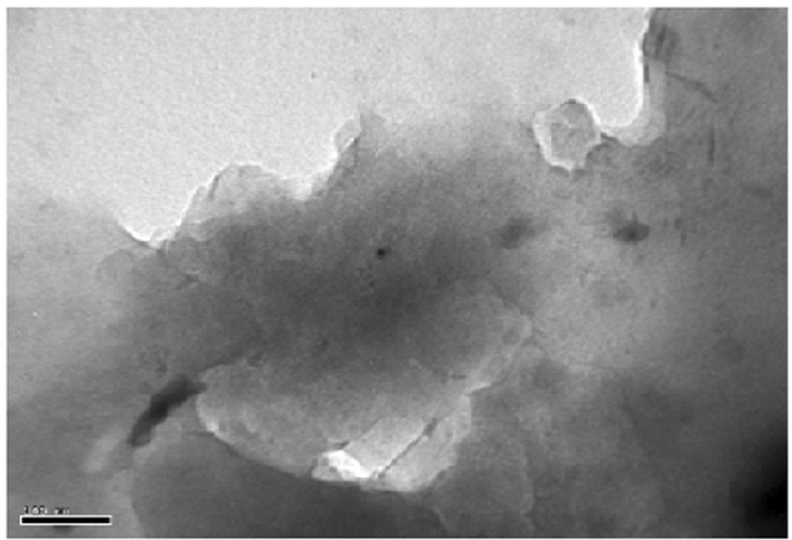

(c)

Figure 6. TEM of (a) gly $_{2}$, (b) gly $_{3}$ and (c) gly $_{4} / \mathrm{MMT}$ nanocomposites.

6.5 - 7 (OH bands appeared). $\mathrm{H}_{2} \mathrm{O}$ molecules appeared at 3.2 - 3.3 ppm.

\section{Conclusion}

Homo and several block glycopolymers were successfully grafted from MMT surface by using SI-ATRP .That was achieved firstly by organic treatment of MMT with a surfactant (BHPAC) which had affinity to react with ATRP initiator (2-EiBBr) and led to immobilizing ATRP initiator onto clay surface. ATRP functionalized clay 


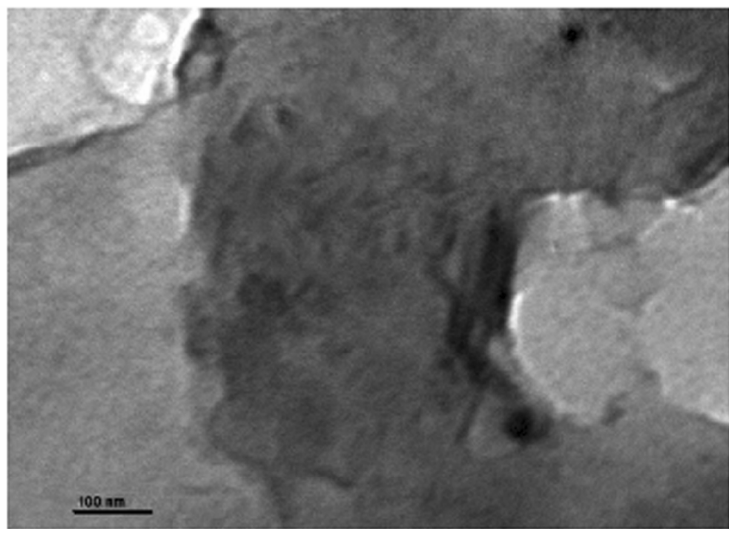

(a)

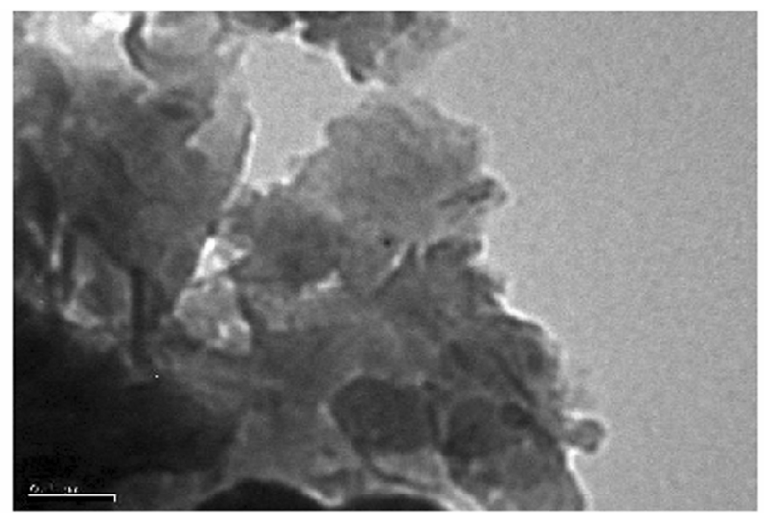

(b)

Figure 7. TEM of (a) gly $_{1}$ and (b) gly $_{5} / \mathrm{MMT}$ nanocomposites.

surface initiator was then used for homo and co-polymerization of gly in presence of bpy/CuBr and 2-EiBBr as sacrificial initiator. Some of the resulting nanocomposites ( gly $_{2}$, gly $_{3}$ and gly $/$ MMT) showed exfoliated structures and others (gly 1, p-MMA, p-St and gly $/$ MMT) showed partially exfoliated structures as judged by XRD analysis and TEM images. The grafted polymers onto clay surface were detached from the clay surface and their structures were confirmed by ${ }^{1} \mathrm{HNMR}$ where well defined structures were detected and this confirmed the controlled nature of the polymerization processes. Isopropylidene groups in gly $/ \mathrm{MMT}_{1}$ were deprotected and gly $_{1}$ was converted into multi-hydroxy glycopolymer $\left(\right.$ gly $\left._{6}\right)$ which was characterized to be used in future versatile applications in bionanotechnology.

\section{REFERENCES}

[1] S. V. Krishna and G. Pugazhenthi, "Properties and Thermal Degradation Kinetics of Polystyrene/Organoclay Nanocomposites Synthesized by Solvent Blending Method: Effect of Processing Conditions and Organoclay Loading,” Journal of Applied Polymer Science, Vol. 120, No. 3, 2011, pp. 1322-1336. doi:10.1002/app.33179
[2] R. Wilson, T. S. Plivelic, A. S. Aprem, C. Ranganathaiagh, S. A. Kumar and S. Thomas, "Preparation and Characterization of EVA/Clay Nanocomposites with Improved Barrier Performance,” Journal of Applied Polymer Science, Vol. 123, No. 6, 2012, pp. 3806-3818. doi:10.1002/app.34966

[3] S. Pavlidou and C. D. Papaspyrides, "A Review on Polymer-Layered Silicate Nanocomposites," Progress in Polymer Science, Vol. 33, No. 12, 2008, pp. 1119-1198. doi:10.1016/j.progpolymsci.2008.07.008

[4] H. Roghani-Mamaqani1, V. Haddadi-Asl, M. Najafi and M. Salami-Kalajahi, "Synthesis and Characterization of clay Dispersed Polystyrene Nanocomposite via Atom Transfer Radical Polymerization,” Polymer composites, Vol. 31, No. 11, 2010, pp. 1829-1837.

[5] M. A. Tasdelen, J. Kreutzer and Y. Yagci, "In situ Synthesis of Polymer/Clay Nanocomposites by Living and Controlled/Living Polymerization,” Macromolecular Chemistry and Physics, Vol. 211, No. 3, 2010, pp. 279-285. doi:10.1002/macp.200900590

[6] C.-P. Li, C.-M. Huang, M.-T. Hsieh and K.-H. Wei, "Properties of Covalently Bonded Layered-Silicate/Polystyrene Nanocomposites Synthesized via Atom Transfer Radical Polymerization,” Journal of Polymer Science Part A: Polymer Chemistry, Vol. 43, No. 3, 2005, pp. 534-542. doi:10.1002/pola.20536

[7] R. Barbey, L. Lavanant, D. Paripovic, N. Schuwer, C. Sugnaux, S. Tugulu and H.-A. Klok, "Polymer Brushes via Surface-Initiated Controlled Radical Polymerization: Synthesis, Characterization, Properties, and Applications," Chemical Review, Vol. 109, No. 11, 2009, pp. 5437-5527. doi:10.1021/cr900045a

[8] B. R. Coada, Y. Lua and L. Meagher, "A Substrate-Independent Method for Surface Grafting Polymer Layers by Atom Transfer Radical Polymerization: Reduction of Protein Adsorption," Acta Biomaterialia, Vol. 8, No. 2, 2012, pp. 608-618. doi:10.1016/j.actbio.2011.10.006

[9] R. Fleet. E. T. A. van den Dungen and B. Klumperman, "Synthesis of Novel Glycopolymer Brushes via a Combination of RAFT-Mediated Polymerisation and ATRP," South African Journal of Science, Vol. 107, No. 3-4, 2011, pp. 1-11. doi:10.4102/sajs.v107i3/4.424

[10] E. B. Kheireddine and X. F. Huang, "Glyco-Nanomaterials: Translating Insights from the 'Sugar-Code' to Biomedical Applications,” Current Medicinal Chemistry, Vol. 18, No. 14, 2011, pp. 2060-2078.

[11] T. Chen, D. P. Chang, T. Liu, R. Desikan, R. Datar, T. Thundat, R. Berger and S. Zauscher, "Glucose-Responsive Polymer Brushes for Microcantilever Sensing," Journal of Materials Chemistry Articles, Vol. 20, No. 17, 2010, pp. 3391-3395. doi:10.1039/b925583d

[12] C. Gao, S. Muthukrishnan, W. Li, J. Yuan, Y. Xu and A. H. E. Müller, "Linear and Hyperbranched Glycopolymer-Functionalized Carbon Nanotubes: Synthesis, Kinetics, and Characterization,” Macromolecules, Vol. 40, No. 6, 2007, pp. 1803-1815. doi:10.1021/ma062238z

[13] K. Yu and J. N. Kizhakkedathu, "Synthesis of Functional Polymer Brushes Containing Carbohydrate Residues in 
the Pyranose form and Their Specific and Nonspecific Interactions with Proteins," Biomacromolecules, Vol. 11, No. 11, 2010, pp. 3073-3085. doi:10.1021/bm100882q

[14] A. Pfaff, V. S. Shinde, Y. Lu, A. Wittemann, M. Ballauff and A. H. E. Müller, "Glycopolymer-Grafted Polystyrene Nanospheres,” Macromolecular Bioscience, Vol. 11, No. 2, 2011, pp. 199-210. doi:10.1002/mabi.201000324

[15] K. R. Yoon1, B. Ramaraj, S. Lee, J.-S. Yu and I. S. Choi, "Surface-Initiated Atom-Transfer Radical Polymerization of 3-O-methacryloyl-1, 2:5,6-di-O-isopropylidene- $\alpha$-Dglucofuranoside onto Gold Surface," Journal of Biomedical Materials Research Part A, Vol. 88, No. 3, 2009, pp. 735-740.

[16] Y. Someya, T. Nakazato, N. Teramoto and M. Shibata, "Thermal and Mechanical Properties of Poly (Butylene Succinate) Nanocomposites with Various Organo-Modified Montmorillonites," Journal of Applied Polymer Science, Vol. 91, No. 3, 2004, pp. 1463-1475. doi:10.1002/app.13366

[17] H. Datta, A. Bhowmick and N. Singha, "Tailor-Made Hybrid Nanostructure of Poly(Ethyl Acrylate)/Clay by
Surface-Initiated Atom Transfer Radical Polymerization,” Journal of Polymer Science Part A: Polymer Chemistry, Vol. 46, No. 15, 2008, pp. 5014-5027. doi:10.1002/pola.22829

[18] K. Ohno, Y. Tsujii and T. Fukuda, "Synthesis of a Well-Defined Glycopolymer by Atom Transfer Radical Polymerization," Journal of Polymer Science Part A: Polymer Chemistry, Vol. 36, No. 14, 1998, pp. 2473-2481. doi:10.1002/(SICI)1099-0518(199810)36:14<2473::AIDPOLA5>3.0.CO;2-U

[19] H. Böttcher, M. Hallensleben, S. Nub, H. Wurm, J. Bauer and P. Behrens, "Organic/Inorganic Hybrids by 'Living'/Controlled ATRP Grafting from Layered Silicates,” Journal of Materials Chemistry, Vol. 12, No. 5, 2002, pp. 1351-1354. doi:10.1039/b110819k

[20] K. Ohno, T. Morinaga, K. Koh, Y. Tsujii and T. Fukuda, "Synthesis of Monodisperse Silica Particles Coated with Well-Defined, High-Density Polymer Brushes by Surface-Initiated Atom Transfer Radical Polymerization," Macromolecules, Vol. 38, No. 6, 2005, pp. 2137-2142. doi:10.1021/ma048011q 